\title{
Sobre teología de la historia
}

\section{ANDRES TORNOS}

Se ha dicho muchas veces que el Dios de la revelación judeo-cristiana se manifiesta en la historia más bien que en los fenómenos de la naturaleza o en las profundidades del ánimo, y que precisamente esto caracterizaría a las religiones bíblicas frente a otras religiones.

También se ha opinado que en la religión del Antiguo Testamento, al tratarse al pueblo elegido como a quien arriesga su ser o su hundimiento en un proceso de siglos, se pusieron las bases para concebir el movimiento de la historia como lugar y forma en que los hombres podemos acceder a nuestro ser más pleno. El Nuevo Testamento habría sido apertura de toda la humanidad, hasta el final de los tiempos, hacia esa realización salvadora: así se habría planteado el diseño de una historia universal destinada a entenderse como trama y medio de la realización de lo humano.

Sobre esto se basaría el parecer según el cual la comprensión filosófica de la historia como proceso en que la humanidad debe crecer y cumplirse hasta su verdadera medida, no constituye en definitiva sino una transposición al orden profano de aquella idea religiosa de salvación en la historia.

Sin embargo tales ideas tropezarían con la constancia de un hecho: ni en el Antiguo ni en el Nuevo Testamento existe una palabra cuyo sentido se corresponda con el que tiene en ellas nuestro término whistoria». ${ }^{1} \mathrm{Y}$ si no existe esa palabra, tno debe pensarse que el concepto o idea correspondientes desempeñaron una función de poco relieve en la lectura de los sucesos y experiencias con que los judíos y los prime- ros cristianos realimentaban su fe y su identidad social?

En mi opinión lo que ha ocurrido es que el comienzo de la teología de la historia debe plantearse dando al nombre «historia» otro significado distinto del que tiene cuando se la considera como trama unitaria y progresivamente adecuada para la realización del hombre. Pero eso no querría decir que fuera indiferente para los judios y los primeros cristianos el esfuerzo por comprender los hechos del mundo y por rimar con ellos el ejercicio y mantenimiento de la fe.

En orden a buscar esta comprensión y a explanar lo intentado en ella sí que aparecen un vocabulario específico y unos conceptos compartidos, tanto en el Antiguo como en el Nuevo Testamento. Con arreglo a éstos los sucesos del mundo y la participación que uno puede tener en ellos se leen en relación con el plan salvador de Dios, no suponiéndose nunca que lo exteriormente mundano es indiferente para la fe, o que ésta requiere únicamente el ser acogida mediante actos internos de la conciencia, o que llama a una salvación puramente extramundana. La lectura de los hechos mundanos requerida para ejercer esa clase de fe, o sea lo pretendido por la teología de la historia, aparece desde este punto de vista como indisociable del judaísmo y el cristianismo.

Intentaré exponer cómo suele hacerse esta lectura en la Biblia, las principales formas de realizarla que han practicado después los creyentes y las posiciones que hoy adoptamos con relación a dicha lectura. 


\section{Revisión de los términos y conceptos biblicos}

Según el Nuevo Testamento nada de lo que ocurre puede dejar de contribuir a que últimamente se manifieste aquella bondad y generosidad de Dios que Él libremente, mediante el Evangelio, quiere dispensar a los que ama (ver por ejemplo R 8,28; Ef 1, 3-11). Esa bondad en un tiempo habría estado dirigida primariamente a los judíos pero ahora por Jesús se ha abierto a todos (ver Ef 2, 4-7). Pablo cree estarle encomendado, por llamamiento divino, el anuncio de este cambio de la situación del mundo (Ef $3,2-10)$ y en la Carta a los Gálatas lo reivindica remitiéndose a la buena lectura de la repercusión pública de su predicación, hecha por las Iglesias de Judea (una apelación a shechos de historia»).

Precisamente aquella bondad de Dios, generosa y libre, es lo llamado en el Nuevo Testamento gracia y, en el Antiguo, «Jesed ${ }^{2}{ }^{2}$ Tener "jesed" es, vista la cosa desde los creyentes judíos y cristianos hacia el interior de Dios, el rasgo más importante del ser divino: empapa todo el Antiguo Testamento, desde Abraham $^{3}$ y Moisés ${ }^{4}$ hasta la época de los salmos, ${ }^{5}$ y en el Nuevo Testamento, fuera de las innumerables alusiones de Pablo, resultaria central para Jesús mismo. ${ }^{6}$ Por lo demás esa misma bondad de Dios, al mirar uno con fe hacia los hechos del mundo, aparecería como volcándose en la creación de todo lo bueno que existe ${ }^{7}$ y dirigiendo con sabiduria los acontecimientos hacia el bien y el mantenimiento de sus promesas. ${ }^{8}$

Con esto tenemos casi todos los elementos principales de la teología bíblica de la historia, o sea de la necesidad inscrita en la religión judeo-cristiana, de "leer" los hechos del mundo con arreglo a la fe. El Dios de esa religión es un
Dios "compasivo y misericordioso" (Ex 34,6 ): quiere en todo el bien de los suyos, también en lo terreno y no sólo en lo espiritual; adernás se vincula con los hombres mediante promesas y debe scr reconocido en el mundo. Consiguientemente no puede menos de guiar "conforme a su gran sabiduria» lo que en el mundo ocurre y un creyente necesita orientar su vida teniéndolo en cuenta.

Pero todo esto, si no hubiera algo más, sería demasiado sencillo y la tarea de entender los sucesos terrenos no necesitaría inculcarse mucho, ni tendría demasiado valor el glorificar a Dios cuando se los comprende bien. Este «algo» de lo cual no hemos hablado hasta ahora es el mal del mundo. Él no procederia de Dios y sin embargo se haría presente por todas partes, tanto entre los elegidos como entre los ajenos a la promesa. Su presencia y dinámica oscurecería constantemente el curso de los hechos, el cual, conforme a la bondad y sabiduría de Dios, debería transparentar siempre bondad. Y ese oscurecimiento habría de ocurrir porque la gran paciencia y longanimidad de Dios ( $R 2,4 ; 9,22$ ), queriendo dar tiempo a todos y no perjudicar a los inocentes, ${ }^{9}$ permite constantemente que los hombres y las naciones sigan sus caminos (Act 14, 16-17).

Esta es la creencia constante de los judíos y de los primeros cristianos, que se ha mantenido por lo demás hasta hoy, como sobradamente sabemos, en los creyentes tradicionales. Según ella lo que hace dificultad para leer los hechos con fe, creando la necesidad de una teología de la historia, son aquellos desarrollos de las cosas que sobrevienen por repercusión de iniciativas torcidas de los hombres. Y éstas crean dificultad porque, siendo Dios quien es, no pueden dejar de integrarse, a pesar de sí mismas, en posibilidades de hacer senti- 
do que les vienen de través; en líneas abiertas a un desenlace donde se sobreponga la bondad de Dios.

Por eso en los planteamientos bíblicos el ejercicio de la comprensión del devenir se dirige ante todo a interpretar aquellos hechos, sucesos y desarrollos sueltos que tenderían a escandalizar, y los interpreta integrándolos en procesos limitados. $\mathrm{Ni}$ busca otras totalizaciones que las del plan de Dios, ni en ningún caso cuenta con que sel buen entendedor’ descubrirá en la sustancia interna de los hechos los significados que debe buscar. Así, siendo esta búsqueda la que determina la forma de elaborarse el "constructo" mediante el cual se sintetiza en la Biblia el devenir de los sucesos del mundo, ese constructo no será como el elaborado por la filosofía moderna de la historia en función de lo que ella por su parte busca. El constructo conceptual del discurso bíblico denotará el conjunto de los hechos sueltos, abiertos a un constante integrarse en la línea del plan de Dios por obra de Dios, no por lo que los hechos son en sí. En cambio el constructo con el que la mentalidad moderna sintetiza el conjunto de los hechos del devenir, toma a éstos como lo quiere la búsqueda propia del actual historiador, el cual se esfuerza por comprender ese devenir tal como ocurre en virtud de lo que son internamente los hechos mismos.

Esto ultimo es lo actualmente llamado historia y desde un punto de vista religioso no interesaba especialmente a los judíos y a los primeros cristianos. En cambio eran muy importantes para su buen análisis creyente de la realidad. según hemos ido viendo, los conceptos de "plan de Dios* (oikonomía), «jesed" o bondad creativa, sabiduría, designios y juicios de Dios, grandes hechos de Dios ("magnalia Dei»), tribulaciones de los elegidos, pecados odiosos («abomi- naciones»), designios escandalosos de los hombres, etc.

\section{Formas posteriores de realización de la teologia de la historia}

En la época de Jesús había alcanzado gran popularidad entre los judíos una manera creyente de «leer" los acontecimientos que no databa de mucho tiempo atrás: la apocalíptica. Ésta por una parte retenía los conceptos y convencimientos básicos de la tradición judía sobre la conducción por Dios de los hechos del mundo, pero por otra parte les daba un giro particular y los instrumentaba al servicio de otros intereses.

Por ejemplo entendían «la bondad de Dios para con sus elegidos" como poder que trazaba entre buenos y malos una línea tajante. Concebía a los designios de Dios de una manera rígida, articulándolos en sucesivos pasos o momentos que habrian de cumplirse, por supuesto, a costa de los no elegidos, para los cuales no se tenía ninguna contemplación. Y finalmente instrumentalizaban ideológicamente la lectura de los hechos para legitimarse con ella siempre a sí mismos, en vez de preguntarse qué debían hacer. Por eso miraban en todo caso al futuro con curiosidad, pero no por empeño de orientar sus vidas: las tenían por bien orientadas.

Según los evangelios parece que muchos contemporáneos de Jesús vieron en Él y en lo que Él hacía signos apocalípticos, y tal vez el mismo Jesús no era del todo ajeno a esa manera de entender su propio llamamiento y actividad. En todo caso chocó con los más apocalípticos de sus conocidos por tres motivos al menos: porque Él no aceptaba la división del mundo entre buenos y malos, porque su interés por los designios de Dios buscaba la realización de esos designios y no complacer curiosidades 
de autosatisfechos, y porque no tenía ni admitía la pretensión de querer interpretar los planes de Dios hasta el detalle de adivinar en qué paso o momento de ellos ocunirian determinadas cosas.

Entre los primeros cristianos estuvo muy extendida esta clase de apocalíptica, como lo testimonian los textos de Marcos 13, Mateo 24 y Lucas 21, 5-36, además del Apocalipsis de Juan. Se comparte una fe sin fisuras en que las imágenes apocalípticas revelan un plan de Dios para el bien de todos los que acogen a Jesús, plan gracias al cual se acercan los creyentes por sus pasos cumplidos a un vivir esplendorosamente bendecido - por cierto que imaginado muy terrenalmente. ${ }^{10}$

Ello ha legado para la refiexión cristiana más o menos rigurosa de siglos posteriores una orientación que algunos piensan que pertenece esencialmente a la teologia de la historia, como paso previo a la construcción de los intentos interpretativos de ésta: el establecer los «tipos»o imágenes del devenir que pueden considerarse sólidamente anclados en la tradición de la fe, por su enraizamiento en las "escrituras sagradas" y en la práctica aceptada de las Iglesias."11 Por ejemplo el éxodo o salida de Egipto, las «plagas» atormentadoras de los malos, el destierro (ide Babilonial), la exaltación de los humildes (en la figura de David o de Ana, madre de Samuel), la justificación de los injustamente condenados (como la de José, vendido por sus hermanos y encarcelado por el faraón), el adelgazamiento de los colectivos portadores del futuro de Dios (aresto de Israel»), etc. Estas imágenes del devenir señalarían modos comprobadamente divinos de reconducirse lo cscandaloso de la historia y de hecho muchos colectivos creyentes se han inspirado constantemente en ellos para darse razón de su lugar en la sociedad y en la Iglesia y para explanar sus esperanzas: desde Pablo (ver 1 Cor 10, 8-11) hasta comunidades inspiradas en la teología de la liberación.

A partir de aquí me parece que empiezan a aparecer los problemas que hoy podríamos reconocer como más nuestros. Tal como yo los veo se referirían a la articulación estructural de la comprensión teológica de la historia, a la clase de teleología universal que le es propia, a la autoria de la historia que esa comprensión puede reconocer y a la unidad y continuidad del devenir total de los hechos del mundo con que ella acepta contar para sus indagaciones. De un modo especial se me hacen presentes estos problemas respectivamente en Agustin, Bossuet, la historiografia del siglo $\mathrm{XIX}$, la de los católicos progresistas del $\mathrm{Xx}$. Hoy estaríamos asistiendo al nacimiento de nuevos enfoques.

De Agustín suelen recordarse sobre todo, con relación a las relaciones fehistoria, los libros sobre "La Ciudad de Dios». La perspectiva desde la cual éstos discurren le viene dada a su autor por la crítica del cristianismo dispersa entonces en la sociedad romana y expresada por Celso: con la recepción de la fe se han acumulado los problemas en la sociedad romana y se ha acelerado su decadencia; el cristianismo como fuerza histórica es una amenaza.

Frente al optimismo oficial de los jerarcas cristianos, los cuales en Occidente creen que la cristianización del imperio ha sido un bien para el mundo, esta crítica levanta la cuestión de cómo se articula con el proceso histórico la dinámica de existencia de la Iglesia. Vistas las cosas desde la fe, zno es la Iglesia portadora de las esperanzas del mundo? ¿No debe estructurarse la lectura de lo terreno diferenciando lo dependiente de la institución eclesial, que siempre induciría efectos positivos, de lo que pervierte o dificulta la marcha de esa institución eclesial? 
Agustín no acepta ese enfoque. Anunciada la fe de Jesús, dos ciudades (o más bien ciudadanías, modos de convivir en sociedad) existirian en la historia: la de Dios y la terrena (nosotros diríamos «la terrenistan). La primera originada por el amor de Dios hasta el desprecio de uno mismo, la segunda originada por el amor de uno mismo hasta el desprecio de Dios. La ciudadanía de Dios no se coextiende con la pertenencia a la Iglesia institucional ni con esta misma, porque la Iglesia es pecadora a la vez que santificada. Sin embargo el poseer esa ciudadanía no es una cuestión puramente mística e interna: implica un amor a Dios activo en lo terreno, polarizado hacia la unión en comunidades de fe socialmente visibles, sin lo cual se desmiente a sí misma. En orden a leer la marcha de la historia teniendo en cuenta a Dios no es acertado el estructurar esa lectura por referencia autoconfiada (o agresiva) a lo institucional de la Iglesia, pero si es menester estructurar tal lectura en relación con el llamamiento desafiante de Jesús a un amor activo, potenciado por la fucrza de una fe vivida con otros.

En la concepción creyente de la buena lectura del devenir se incorpora con esto el convencimiento de que lo ocurrido con Jesús divide y estructura a la historia. Pero no se extrae de ese convencimiento la consecuencia de que lo bueno de la historia viene de la Iglesia visible, o de que nada hay en ésta que dañe a la marcha de la historia.

La Edad Media no produce puntos de vista nuevos, si es que no contamos entre ellos los reflorecimientos de la apocalíptica aparecidos a principios del segundo milenio ${ }^{12}$ Pero a partir del siglo $\mathrm{XVI}$, con la multiplicaciôn de los cambios de la imagen del mundo y los dramáticos efectos de un ejercicio recrecido del poder, va a intensificarse la demanda de comprender hacia dónde van las cosas y qué ocurre con la humanidad. En la literatura cristiana ha tenido especial repercusión lo elaborado por Bossuet acerca de ello en su "Discurso sobre la Historia Universal». ${ }^{13}$

Agustín pensaba a partir de unos hechos y desafios concretos; para Bossuet el desafío lo constituye el todo de la historia, pues ésta se plantea en su tiempo como espectáculo total. Además Agustín pensaba cristológica y eclesialmente, Bossuet por una parte piensa desde el Dios de la filosofía, elevado excelsamente sobre el mundo, y comprende a Jesús desde esa idea de Dios en vez de comprender a Dios desde Jesús; por otra parte toma su pensar eclesial por el pensar razonable de cualquier persona del mundo. El Dios, pues, de Bossuet es el Dios providente y bueno con todos, y Jesús manifiesta en el tiempo el ser y voluntad de Dios - pero ni rompe el tiempo ni lo innova. Un mundo hecho por ese Dios no puede sino encaminarse al bien y la lectura creyente de la historia lo descubre cuando es posible y lo cree por fe cuando no entiende.

"Todo va bien", eso es lo que la lectura creyente de la historia le hace decir a Bossuet, absorto en la necesidad de reconocer una teleología oculia en los hechos. «La mano invisible» de que más tarde hablara Adam Smith es aquí la mano de Dios. La lectura de la historia parece con ello refugiarse en un sublime no saber. Pero ha comenzado un tiempo en que la cultura quiere saber. $Y$ como en la física de Newton los planetas han comenzado a orbitar conforme a leyes propias, trazadas en el principio de la creación por un Dios que desde ese inicio deja marchar sólo al mundo, también la lectura de la historia va a buscar la dinámica interna de un acontecer en que el contar con algún intercalarse de intervenciones divinas empieza a resultar absurdo. 
En el campo profano sabemos que esto llevó a elaborar una ciencia de la historia centrada en conocer las variables de que internamente debe depender el curso y desenlace del desarrollo de las naciones y de toda la humanidad: de su poder, de su prosperidad, de su cultura y artes, últimamente de su economia. El instrumental de conceptos y métodos requerido para ello se afina paso a paso. $Y$ viene a construirse un logos del acontecer que preside sobre los agentes histốricos, por el ahora despojados, al parecer para siempre, de su privilegio de decidir autocráticamente sobre el mundo.

Las orientaciones oficiales de la Iglesia católica, en la medida en que persisten en mirar con sobrenaturalismo y voluntarismo al curso de la historia, parecen volverse más anacrónicas que nunca. $\mathrm{Y}$ sin embargo creo que paradójicamente no están sino demasiado penetradas por la cultura de su tiempo. También ellas miran al devenir del mundo como necesariamente sujeto a un logos que se sobrepone a los intentos humanos. Lo que precisamente ocurre es que ellas creen tener demasiado claro ese logos: lo dan por expresado en una revelación cristiana legitimadora, en favor de ellos, de una clarividencia y un poder superiores. Por eso creen poder y deber hablar con una autoridad que pasa por alto lo que no son sus elevadas ideas: los análisis precarios de la sociedad y del poder, la aportación de lo que luego se han llamado ciencias humanas, en una palabra: la legitimidad de la autoría humana de la historia.

En una cosa se parecen por tanto los análisis del acontecer nacidos de la primera historiografía profana y los operantes en la oficialidad de la Iglesia durante el siglo XIX: unos y otros minimizan el peso de las originales aportaciones de los agentes humanos en aras de un logos que impera sobre éstos: el lo- gos profano del devenir en una parte, el logos supernaturalista del devenir en otra. Hemos llegado a comprender que en ambos casos se escondía detrás de todas las explicaciones una razón partidista, legitimadora de algún poder.

Si en el siglo XIX la discusión eclesiásticamente viva trató sobre la autoría de los encaminamientos históricos (y por eso las autoridades eclesiásticamente siempre habrian intentado decir "no lo pretendemos nosotros, es Dios quien lo quiere y en su nombre juzgamos»), en el siglo $\mathrm{XX}$ alcanza a los cristianos la problemática de la totalización de la historia que había tomado forma fuera de la Iglesia a fines del XviI. Primero participan de ella solamente unos pocos creyentes progresistas y entre ellos nace una lectura del devenir del mundo, antropológicamente fundada, desde la cual se determina el significado de Jesús y el modo de descifrar y valorar lo aportado por la fe cristiana. Esa antropología es por supuesto, hasta en sus versiones marxistas, un esencialismo humanista englobante de todo pensar teórico y práctico. De conformidad con dicho esencialismo carece de sentido en la historia lo que no implique para toda ella, por decirlo con palabras de Hegel muchas veces recogidas por los teólogos, un avance unitario de la razón y de la libertad.

No es extraño que en este contexto la lectura creyente de la historia haya venido a querer practicarse como sanálisis de la realidad" susceptible de compartirse por toda pcrsona honesta. También en cuanto a esto muchos cristianos han querido pensar y han pensado como hijos de su tiempo. Entre ellos la historia profana del mundo es una única historia, y por supuesto la única verdadera historia que podría interesar a la teología. "La separación de una historia de salvación centrada en Cristo del conjunto de la historia del mundo y la afirmación de que 
aquella es la historia verdadera y esencial no es sino un absurdo para el pensar, tanto antiguo como reciente., ${ }^{14}$

Pero no todos sacan las mismas conclusiones de este convencimiento. Han surgido desde luego muchas reformulaciones del llamamiento cristiano a participar en lo que se considera movimiento único de la historia profana y sagrada, leído con una lectura que se recubre más o menos con la lectura progresista de la historia ${ }^{15}$ y oficialmente la Iglesia católica habria adoptado esta línea en el Concilio Vaticano II. Pero un sector significativo de teólogos ha mantenido que, dado que la historia es lo que es, profana de parte a parte y carente de contenidos investigables sólo con instrumentos conceptuales revelados, todo intento de lectura teológica de la historia es una mitologización que debe resolverse con una explanación verdaderamente teológica de la historicidad. Suele pensarse en Bultmann cuando se recuerdan estas ideas, aunque ellas han penetrado entre los protestantes hasta círculos poco bultmannianos y no son del todo ajenas, a mi parecer, a los enfoques del último von Balthasar. ${ }^{\text {to }}$

\section{Cuestiones y problemas de hoy}

Quizás el mayor desafio con que se enfrenta hoy la teología de la historia es la crisis que en el saber profano roe a la denominación misma de historia universal. Ésta se ha convertido para muchos en una fórmula retórica vacía por pérdida total de la confianza en los criterios con que hasta hace poco se venía interpretando lo que significaba «avance universal de la razón y la libertad». Pero como al mismo tiempo el interés por la historia no ha decaído ni renunciado al rigor de su empeño científico, lo que queda es una historia fragmenta- da en cuyo interior parecen carecer de sentido las cuestiones últimas que sobre el acontecer se plantea la teología.

El debate entre modernidad y postmodemidad se introduce con esto en la reflexión religiosa. $Y$ en verdad fuerza a ésta a una opción difícil. Porque la concepción del avance unitario de la historia no sólo ha sido tan central en los últimos siglos de la cultura europea que su oscurecimiento y crisis se experimentan como un oscurecimiento de las razones últimas del vivir, es que además esa crisis pone en cuestión la unidad de la razón humana en lo ético-práctico primeno, pero por ello mismo también la validez de toda pretensión de universalidad. Así el cristianismo en cuanto religión universal queda también puesto en cuestión.

Baste con señalar el problema, dado que en el espacio de esta nota no cabe entrar a discutirlo. ${ }^{17}$ El exige una nueva reflexión sobre las totalizaciones de la lectura de la historia hechas por la teología, y sobre la validez última de las lecturas de los hechos que ella puede ofrecer.

Pero otro frente de problemas, menos concienciado hasta el momento, se reabre también hoy: el de la autoría de la historia, que a mi entender no estuvo bien planteado, y mucho menos resuelto, en la época en que surgió. Este problema viene a imponerse por otro componente de la crisis de la modernidad, en el fondo inseparable del de la crisis de la totalización de la historia: el desfondamiento del sujeto humano. Deslegitimado éste al quedar a merced de la fragmentación de sus perspectivas, ellas son un supremo logos múltiple que rige la actuación humana en el devenir del mundo. La historia es un sueño anárquico que nos sueña.

Frente a ello es preciso reconstruir un pensar nuevo sobre la libertad, contando con que ésta sólo desde un suelo de contingencia puede afirmarse como res- 
ponsable, y sólo de modo precario. Ultimamente, a este propósito, se está recalcando en teología la importancia que tendría, para la comprensión del señorio de Dios, el reconocimiento de las vetas de contingencia entreveradas en el devenir mecánico del mundo, según la actual imagen científico-física de la materia; pero apenas se ha entrado en el análisis creyente de lo que eso implica desde el punto de vista de la fe. ${ }^{18} \mathrm{En} \mathrm{mi}$ opinión es el análisis de los factores de contingencia diseminados en el curso onírico de la historia el que puede señalarnos un espacio donde hablar de auto- ría humana y significado de la historia, aunque con un sentido rigurosamente nuevo.

Hoy desde luego la aportación de Bossuet no nos valdría, pues recurrir a la providencia oculta significa renunciar a saber y entender, lo cual suprime a la teología de la historia en vez de enriquecerla. Quizás, a los que algo trabajamos en ella, la tarea que más a mano se nos ofrece es retomar los temas donde los dejó "La Ciudad de Dios", de San Agustín, pero preguntándonos por la autoria de los hechos del mundo y por lo fragmentado que está su encadenamiento.

\section{NOTAS}

1. Ver artículo de O. Ploger y E. Dinkler respectivamente sobre el concepto de historia en el Antiguo y en el Nuevo Testamento, el Real Laxikon fuir Geschichte und Gegerwart, t. II, ed. 3, col. 1.473. 1.482.

2. Una excelente investigación sobre el trasfondo histórico-religioso de la comprensión del ajesed $n$ o gracia en que creian los cristianos primitivos está incluida por E. Schillebeeckx al principio de su obra Cristo y los cristianos, traducida en Cristiandad, Madrid, 1982.

3. Gen $18,3,17-19$

4. Ver $\operatorname{Ex~} 33,18-23$ con $34,5-9$.

5. Ver el 136, que recitaban los judios después de las ceremonias de la Pascua hasta la época evangélica y que probablemente recitó Jesús mismo según Mc 14, 26 .

6. Lucas pone bajo el signo de ese sbeneplácito divinom la aparición de Jesús en 2, 14; el mismo Lucas en 10, 21-22 y Mateo en 11, 25-27 hacen entrar en extasis a Jesús con el reconocimiento de que el "bjesed" o bondad de Dios elige sobre todo a los pobres, etc.

7. Ver por ejemplo el mismo salmo 136 antes citado.

8. Lucas alude a cóno es tarea obvia para quien piensa desde la fe el rastrear esa sabiduria en las apariencias contradictorias del proceder austero de Juan Bautista y el abierto y relajado de Jesús (cap. 7. 28-35). Ver también Pablo a los Romanos 11 33-36, sobre el rechazo del pueblo judio.

9. Los Evangelios insisten mucho en to primero, mediante la parábolas del trigo y la cizaña o, por ejemplo, la del hijo pródigo. Ello lleva consigo la salvaguarda de los inocentes, que esta muy logradamente expresada en el cap. 4 del libro de Jonás.
10. Es lo que se ha llamado "milenarismos. Sobre el sentido y la difusión que el tuwo en los principios del cristianismo ver A.J. Visser aA Bird's eye. View of Ancient Christian Eschatologym, Numen, 14 (1967), 422.

11. Ver artfculo "Typos in der Schrift", en Lexikon fur Theologie und Kirche, tomo 10, col. $422 \mathrm{sec}$.

12. Diversas alusiones de E. Bloch y la novela $E$ l nombre de la rosa han relanzado el interés por la lectura de la historia que hicieron Joachim de Fiore y diversos grupos posteriomente muy relacionados con los franciscanos. Esa lectura habría alimentado la ideologia de sectores sociales marginados, empenados en distintas formas de subversion.

13. Todavía el año 1940 se reeditó en castellano el "Discurso..." de Bossuet en Barcelona, Cervantes. Es curioso que en 1589 el jesuita Pedro de Rivadeneyra, que habia escrito un discurso-arenga para los participantes en la expedición de la Armada Invencible, publique un Tratado de la tribulación en cuya segunda parte trata de explicar los «desastresn bistóricos de los buenos católicos en sus luchas con los herejes. Hace desde luego una rudiInentaria teología de la historia que se pregunta más bien por lo que el en la historia no comprende como progreso; por los sufrimientos y los absurdos; el individuo desempeña por supuesto un papel nucho más importante que en Bossuet.

14. W. Kreck, Die Zukunft des Gekomntenten, Munich, Kaiser Verlag, 1966, p, 31.

15. Entre ellas incluiria diversos trabajos de Rahner, Pannenberg y Schillebeeckx. Me he ocupado de ello en mi Escatologia I, Madrid, Publicaciones de la Universidad Comillas, 1989, p. 128-130. Una revisión más amplia de la teologia de la historia hasta los años sesenta puede consultarse en W. 
Kasper, "Gnundlinien einer Theologie der Geschichte*, TheolQuarialschrift, 144 (1964), 129-169.

16. Sobre todo en De L'Integration-Aspects d'une Theologie de L'Histoire, Brujas, Desclée de Brouwer, 1970, por ejemplo, p. 185.

17. Como podria fundarse en la fe cristiana una esperanza de alcance universal, en el contexto de crisis de la idea de historia universal, es actualmen. te objeto de activa reflexión teológica. Me he ocupado de ello en Escatología I, op. cit., p. 137-163.

18. Puede consultarse sobre el tema a W. Pannenberg, "The Doctrine of Creation and Modern Scien. ces, Zygon, 23 (1988), 3-21 y a R.J. Russell, "Contingency in Physics and Cosmology $\rtimes_{2}$ ibfd. 23-43,

\title{
La reconstrucción estética de la historia del trabajador (Un diálogo casi posible entre Jünger y Weiss)
}

\author{
JOSÉ LUIS MOLINUEVO \\ Universidad de Salamanca
}

Se exponen dos modalidades de reconstrucción estética de la historia, entretejidas con los avatares de un programa romántico para el que la libertad sólo es posible en la belleza y la tarea del Arte consiste en la edificación de una nueva sociedad ético-política. El diálogo entre ambos autores, de talantes tan diversos, es po-

Pero ¿acaso no debiera yo hacer de la libertad que me concedéis un uso mejor que el de encaminar vutestra atención hacia el campo de las bellas artes? ¿No es por lo menos extemporáneo andar ahora buscando un código del mundo estético, cuando los asuntos del mundo moral ofrecen un interés mucho más próximo y el espíritu filosófico de investigación es requerido $\tan$ insistentemente por los acontecimiento a ocuparse en la obra de arte más perfecta que cabe: el establecimiento de una verdadera libertad política? [...] Si resisto a la tentación y antepongo la belleza a la libertad, creo que puedo hallar disculpa, no sólo en mi afición personal, sino en los principios que justifican esa preferencia. Espero persuadiros de que esa materia no es tan ajena a las necesidades como al gusto del siglo; y aun más: que para resolver en la experiencia el problema político, se precisa tomar el camino de lo estético, porque a la libertad se llega por la belleza. sible desde las actuales experiencias narrativas como experiencias históricas. Su prolongación (no realizada aqui) mostraría algunos límites de las estéticas conternporáneas de la resistencia, los supuestos de esos discursos históricos, así como el ethos que subyace a la vacilante pérdida de la normatividad ética.

\section{El quiebro de la quiebra de un programa romántico}

El envite cstético de Schiller es la invitación a salir de una perplejidad histórica en un dialogo instaurador del espacio de juego social que modere la embestida. El diálogo requiere una clarificación previa de los interlocutores interesados que posibilite los niveles del mismo. Lo que le preocupa a Schiller es la solución del enigma de su tiempo: estamos en una época ilustrada, $y, \sin$ embargo, seguimos en la barbarie política y moral. Una época cuya realidad es la contradicción de sus ideales es una época enferma. ¿Más dosis de cultura? Schiller todavía confía en que los umanantiales de culturas lleguen a limpiar la "podredumbre política". Pero ¿qué es 